\section{La teología política de Schelling en el Freiheitsschrift*}

\author{
Carlos Andrés Ramírez \\ Universidad de los Andes, Colombia \\ https://orcid.org/0000-0002-5192-3409
}

Resumen: Schelling no es reconocido como pensador político. Su Escrito sobre la libertad, en particular, pareciera un texto relevante exclusivamente desde un punto de vista ontológico y teológico. No obstante, es posible interpretarlo en términos políticos considerando (1) su deliberada intervención en cierto contexto histórico-político y sus alusiones al mismo; (2) su lectura en clave ontoteológica de la historia humana y, en ella, del surgimiento de un "nuevo reino"; y (3) su comprensión de la filosofía como impulso a un nuevo tipo de espiritualidad. La suma de esos elementos permite hablar de una teología política en el Freiheitsschrift.

Palabras Clave: Schelling; teología política; metapolítica; ontoteología; mal.

\section{Schelling's Political Theology in the Freiheitsschrift}

Aвstract: Schelling is not acknowledged as a political thinker. His writing Philosophical Inquiries into the Essence of Human Freedom, in particular, seems to be a relevant text from an ontological and theological point of view, but not from a political one. However, it is possible to interpret it in such terms if one considers (1) its deliberate intervention in a certain historical-political context and its allusions to it, (2) its ontotheological understanding of human history and, within it, the emergence of a "new kingdom" and (3) his understanding of philosophy as an impulse to a new kind of spirituality. Such elements allow us to speak of a Political Theology in the Freiheitsschrift.

Key Words: Schelling; Political Theology; Metapolitics; Ontotheology; Evil.

\section{Cómo CITAR:}

Ramírez, Carlos A. "La teología política de Schelling en el Freiheitsschrift". Theologica Xaveriana (2020): 1-27. https://doi. org/10.11144/javeriana.tx70.tpsf

*Artículo de investigación

${ }^{a}$ Autor de correspondencia. Correo electrónico: ca.ramireze@uniandes.edu.co 


\section{Introducción}

Schelling no es reconocido como pensador político. No solo no figuraría en una lista al lado de Aristóteles, Maquiavelo y Hobbes, sino que, en comparación con otros representantes del idealismo alemán, como Fichte o Hegel, se extrańa en su obra una reflexión sobre los asuntos políticos de un calibre comparable al de algunos textos de esos dos contemporáneos. De hecho, con excepción de un breve escrito de juventud como la Nueva deducción del derecho natural (1795), no pueden hallarse en su obra textos dedicados exclusivamente al tema.

Estos temas aparecen ciertamente, y de manera frecuente, en sus diarios y correspondencia, y así mismo ocupan repetidamente pasajes de sus escritos sistemáticos, pero además de que no constituyen el centro de la reflexión de Schelling, en ocasiones parecen figurar solo debido a la pretensión de totalidad de la idea de sistema. Incluso quienes se han ocupado con rastrear las líneas generales de sus reflexiones políticas -como Habermas ${ }^{1}$, Cesa ${ }^{2}$, Hollerbach ${ }^{3}$ o Jäger ${ }^{4}-$ se muestran cautos a la hora de declararlo un pensador político. Y otros como Sandkühler ${ }^{5}$ lo declaran expresamente un pensador "antipolítico". Schelling, dice Sandkühler, vivenció las revoluciones o los intentos de revolución en la Europa de 1789, 1830 y 1848. Su obra constituiría, de comienzo a fin, un esfuerzo filosófico por despolitizar la idea de libertad y, con espíritu declaradamente antirrevolucionario, volcarla, bajo forma eminentemente contemplativa, hacia la esfera de la estética o de la religión.

Frente a esta lectura de Schelling como pensador antipolítico, el presente texto propone considerarlo más bien pensador metapolítico. El concepto de "metapolítica” acoge un variado espectro de significados ${ }^{6}$.

El término, en primer lugar, es usado por la Nouvelle Droite para designar una clase de acción política que no opera en la esfera de la competencia partidista por el poder estatal sino en el conflicto entre mentalidades de larga duración. En esta línea se halla una corriente específicamente religiosa, el llamado "tradicionalismo", que apunta a la recuperación de una experiencia de lo sagrado en el marco de una escatología cristiana. El término, en segundo lugar, es usado por J. Rancière para designar una

\footnotetext{
${ }^{1}$ Habermas, "Dialektischer Idealismus in Übergang zum Materialismus. Geschichtsphilosophische Folgerungen aus Schellings Idee einer Contraction Gottes", 172-227.

${ }^{2}$ Cesa, "Friedrich Wilhelm Joseph Schelling”, 226-231.

${ }^{3}$ Ver a Hollerbach, Der Rechstgedanke bei Schelling. Quellen-Studie zu seiner Rechts- und Staatsphilosophie.

${ }^{4}$ Ver a Jäger, Schellings politische Anschauungen.

${ }^{5}$ Ver a Sandkühler, Freiheit und Wirklichkeit.

${ }^{6}$ Bosteels, Badiou and Politics, 20-34.
} 
de las configuraciones de la filosofía política ${ }^{7}$, una conforme a la cual los fenómenos específicamente políticos son considerados como expresiones de una estructura más profunda, de modo tal que revisten, en consecuencia, un carácter sintomático. En tercer lugar, la metapolítica designa -para A. Badiou y en oposición a la filosofía políticaun tipo de pensamiento filosófico que no se ocupa de lo político como su objeto, sino que más bien se produce en el mismo ejercicio, siempre situado en una coyuntura, de la práctica política por parte de un sujeto constituido en su fidelidad a una verdad ${ }^{8}$.

Schelling puede ser considerado un pensador metapolítico porque, en su filosofía y, en particular, en el Freiheitschrift (1809), se recogen elementos de las varias acepciones del término. Si lo político es sobre todo síntoma -síntoma de procesos de larga duración como la secularización-, el coetáneo imperialismo napoleónico aparece en él como consecuencia, susceptible de ser interpretada en la lógica de la teodicea, de la apropiación de la forma de lo universal por parte de una entidad particular: el Estado. Si el problema de la política es lograr una unidad entre la multiplicidad de seres humanos", su plena resolución no pasa a través de él sino de la instauración de una comunidad posestatal y posimperial cuyo horizonte es el "nuevo reino".

El trabajo de la filosofía, en ese sentido, es posibilitar la relectura de una narrativa cristiana de la historia y, con este trasfondo, una forma filosóficamente mediada de "religiosidad". No hay reino sin religiosidad y, por tanto, sin la resolución del individuo de permanecer fiel al conocimiento de lo genuinamente universal ${ }^{10}$. El papel de la filosofía es entonces intervenir en una particular coyuntura histórica con el fin de inducir, mediante un tipo peculiar de pensamiento y sobre la base de una tradición religiosa, la transfiguración de la identidad personal de los individuos. La filosofía no tiene, al modo de la filosofía política, la política como su objeto -Schelling rechaza todo fraccionamiento de la filosofía en una estética, una ética, etc.- pero no es, por ello, apolítica o antipolítica. El Freiheitschrift no es un texto político por lo que dice sobre lo político sino por lo que él pretende producir, en un plano político-cultural, en su particular coyuntura histórica. Como para el Schelling del Freiheitschrift la filosofía es primordialmente "ontoteología" ${ }^{11}$, puede decirse que dicho texto es una

${ }^{7}$ Rancière, El desacuerdo. Política y filosofía, 106-108.

${ }^{8}$ Gordillo, "La política como pensamiento en la filosofía de Alain Badiou", 39-40.

9 Bubner, Polis und Staat. Grundlinien der politischen Philosophie, 71.

${ }^{10}$ Schelling, Sämtliche Werke VII, 392.

${ }^{11}$ Heidegger, Schellings Abhandlung über das Wesen der menschichen Freiheit (1809), 61-62. Decir que el Freiheitsschrift es una ontoteología pareciera dejar de lado el que, en este texto, por la vía del no-fundamento (Ungrund), hay un manifiesto distanciamiento de la idea de Dios como "sumo ente" y, por tanto, del supuesto "olvido del Ser". No obstante, aun si la descripción de Heidegger, en aras de validar su propia 
(onto)teología (meta)política. El propósito de este ensayo es explicar cómo entiende Schelling tal concepto en consideración de su propia condición histórica, los fundamentos conceptuales del texto y los efectos pretendidos del mismo.

La comprensión de la dimensión metapolítica del escrito pasa así por explicar -en primer lugar- cómo Schelling interpreta, en términos ontoteológicos, su propia situación histórica. En la segunda sección, de la mano de una explicación muy general de los principios ontológicos que guían el Freiheitschrift, se explicará cómo es concebido, desde esas categorías, lo histórico-político. En la tercera sección se expondrá, reconstruyendo tres de las dimensiones del saber teológico-político, cómo el Freiheitschrift busca producir los efectos a los que apunta y generar cierta "espiritualidad"12. Solo en ese marco podrá determinarse el sentido, a la vez teórico y práctico, de la (onto)teología (meta)política en Schelling e introducirlo en el debate contemporáneo sobre este concepto ${ }^{13}$.

\section{Resonancias histórico-políticas del discurso sobre el mal}

El inicio de la modernidad filosófica coincide, para Schelling, con el giro hacia una filosofía centrada en la subjetividad. Este giro conduce en una falsa dirección: "el Yo pienso, yo soy, es, desde Cartesius, el error primordial del conocimiento. El pensamiento no es mi pensamiento y el ser no es mi ser, pues todo es solo de Dios o del universo" ${ }^{14}$. Esta tesis es central en la constitución de la "filosofía de la identidad". No se trata de negar la realidad de la autoconciencia, tal como si el ego fuera una ilusión. Se trata, más bien, de que el ser del ego no es $e l$ ser y que, por tanto, la autoconciencia no puede reclamar el estatus de fundamento ni -como lo señaló Spinoza- atribuirse la autosuficiencia de una substancia.

Con Fichte el lenguaje substancialista es desbancado de la metafísica por el lenguaje de la acción, pero solo se transfigura -según Schelling- la naturaleza del error. Frente al sujeto cartesiano, Fichte entiende la subjetividad como actividad que

lectura de la historia de la metafísica, omite o no sopesa adecuadamente el sentido del Ungrund, resulta adecuada en cuanto esta paradójica noción designa en realidad el límite de este tipo de teoría que es la metafísica. Lo que la teoría puede hacer es permitir pensar en la estructura interna y el desarrollo de un Dios concebido en términos panteístas y que opera, en efecto, como fundamento último de todo. La metafísica es, por tanto, ontoteología. Que la teoría señale sus propios límites internos al recurrir al inefable "no-fundamento" no cambia, en ese sentido, su objeto.

${ }^{12}$ Hadot, La filosofía como forma de vida, 137-151.

${ }^{13}$ Me refiero, obviamente, a toda la secuela de autores que, por diversos caminos, ha hecho eco de los problemas planteados por la Teología política de Carl Schmitt (1922): G. Agamben, R. Esposito, M. Cacciari, P. Kahn, J. Assmann, y H. Meier, entre muchos otros.

${ }^{14}$ Schelling, Sämtliche Werke VII, 148. 
no presupone ninguna substancialidad. El sujeto no es algo dado, ni siquiera para la introspección, pues es algo que se constituye en tanto $-\mathrm{y}$ solo en tanto- se piense. Él solo es en el acto de saber de sí. El ego, como Tathandlung, es acción, y el no-ego no es aquí sino el límite interno y parcial de la actividad yoica. Fichte concibe así la subjetividad sobre la base de la razón práctica: "La razón no puede ser ella misma teórica, si ella no es práctica. No hay ninguna inteligencia posible en el hombre, si no hay en él una facultad práctica. La posibilidad de toda representación se funda en esta última" ${ }^{15}$. Ese ego es considerado algo incondicionado y, en la línea de la metafísica moderna, opera como fundamento.

A pesar de las transfiguraciones a las cuales Schelling somete su "filosofía de la identidad" en el Freiheitschrift, la polémica con Fichte, además de que sigue aquí vigente, es uno de sus ejes. Atacar a Fichte y a toda metafísica subjetivista -tal como lo hace Schelling, de manera programática, en las palabras preliminares del texto ${ }^{16}-$, no es atacar un sistema filosófico más sino es enfrentarse, en clave filosófica, con la mentalidad que subyace a los grandes cambios propios de la Modernidad: el proceso de secularización, el predominio de la técnica, la constitución de un orden político democrático. Schelling trata esa serie de fenómenos histórico-sociales como manifestaciones del mismo Zeitgeist y, entonces, lo reinterpreta como un tipo generalizado, ya no restringido al espacio de la filosofía, de idealismo práctico. La denominación, en el Freiheitschrift, de esa mentalidad, a la cual corresponde filosóficamente el pensamiento temprano de Fichte, es el "mal". Bien dice Schneider al respecto:

El concepto del mal debe ser entendido como forma cifrada del impulso de autonomía del hombre, el cual se descarga tanto en el terror de la Revolución Francesa como en la egomanía económica de las capas sociales prósperas. Malo es quien abusa de la tradición heredada en palabra y acción y, de ese modo, perturba el orden querido por Dios; eso lo hacen tanto el miembro del tribunal revolucionario como el capitalista orientado al provecho. ${ }^{17}$

Fenómenos sociales como las revoluciones o el surgimiento del capitalismo son para Schelling expresiones de un cambio en la conciencia humana de la cual da cuenta el egocentrismo del idealismo práctico. El concepto del mal los redescribe en términos ontoteológicos. La transformación continua de la realidad, en la cual todo lo sólido, todas las creencias, todas las instituciones, la permanencia de la naturaleza

\footnotetext{
${ }^{15}$ Schelling, Sämtliche Werke I, 264.

${ }^{16}$ Schelling, Sämtliche Werke VII, 333.

${ }^{17}$ Schneider, Persönlichkeit und Wirklichkeit. Nachidealistische Schellingrezeption bei Immanuel Hermann Fichte und Christian Hermann Weiße, 498.
} 
misma, se volatilizan, remite, en última instancia, a la infinita capacidad creadora de la subjetividad práctica. Dice al respecto Oesterreich:

En esa versatilidad, en la infinita potencia del poder-ser-otro y de la permanente no-identidad, constituye el mal el modo trastocado de la subjetividad moderna que ha llegado a sí misma, la cual, en la conciencia de su infinito poderposicionador (Setzungsmacht), se pierde en la infinitud vacía de su propia libertad. ${ }^{18}$

Oesterreich habla de poder-posicionador aludiendo, obviamente, a Fichte, para quien el concepto del poner (Setzen) es central en su descripción de la subjetividad como actividad. W. Janke coincide al identificar la crítica a Fichte del Schelling de la filosofía de la identidad con el mal del Freiheitschrift.

En el transcurrir de la teogonía trascendental la Tathandlung de Fichte llega a ser el principio de la caída y el acto primigenio de la pérdida de libertad [...] La libertad del yo aparece como desenlace de un desmoronamiento de la libertad en la cual el yo corporeizado está tan unido a lo finito que el hombre corpóreo se vuelve incapaz de liberarse de esa falta de libertad y restaurar su libertad divina y la necesidad de su esencia. ${ }^{19}$

Para el Schelling del Freiheitschrift, y mucho antes -para él como autor, junto con Hegel, de Sobre la esencia de la crítica filosófica (1803) o del escrito contra Fichte de 1806- la conquista de la plena autonomía de la subjetividad no es la meta del ser humano, sino es el problema que debe ser superado. Si el mal designa, en clave teológica, una serie de procesos históricos ligados a la Modernidad, eso significa que la crítica de Schelling a los mismos, a diferencia de pensadores significativos de la Restauración, no busca simplemente un retorno al viejo orden. Schelling confiere dignidad ontológica a esos procesos, reconoce en ellos una manifestación de la fuerza creadora del espíritu, pero no les atribuye un carácter último. Constituyen más bien una fase de transición.

El mal, como inversión del orden originario de lo particular y lo general en el hombre se manifiesta, por un lado, en la forma de ideologías ${ }^{20} \mathrm{y}$ en la forma, en términos frankfurtianos, de la "razón instrumental". El mal toma la forma de la ideología porque ...todo lo que depende solo del sujeto y, sin embargo, quiere ser visto como verdad, busca reemplazar el carácter de validez general interna por esa validez general externa y así simularlo, es decir, desea hacerse a sí mismo asunto de

\footnotetext{
${ }^{18}$ Oesterreich, Delehrte Absolute. Metaphysik und Rhetorik bei Kant, Fichte und Schelling, 168.

${ }^{19}$ Janke, Die dreifache Vollendung des Deutschen Idealismus. Schelling, Hegel und Fichtes ungeschriebene Lehre, 73.

${ }^{20}$ Ramírez Escobar, “Patologías de la razón. Mal e ideología en Schelling”, 109-160.
} 
todos los sujetos y fundar una secta. Fanático [Schwärmer] es el que quiere formar un enjambre, una secta. ${ }^{21}$

En este pasaje del texto de 1806 contra Fichte, Schelling señala cómo la subjetivización de la razón va de la mano del esfuerzo por reemplazar, como criterio de verdad, la coherencia interna y la sistematicidad por la eficacia de unos conceptos para movilizar el mayor número posible de individuos. Este el momento de la ideologización de los conceptos y de las teorías. No hay que olvidar que Schelling está hablando justamente del periodo que Koselleck denomina el Sattelzeit, en el cual los conceptos no operan tanto como formas de recolección de experiencias pasadas sino como anticipaciones de experiencias posibles y vectores de la movilización política.

La elección del mal es el trasfondo de toda ideología en cuanto es el intento de una perspectiva particular de hacerse pasar por una visión omnicomprensiva de mundo, supuestamente universal, un rasgo, desde una perspectiva marxista, de lo ideológico ${ }^{22}$. El mal, así mismo, toma la forma de la razón instrumental, en cuanto la primacía de la "mismidad" (Selbstheit) sobre la visión del todo (la "voluntad general"), convierte la capacidad humana de trascender, mediante el pensamiento, lo inmediatamente dado a los sentidos, en un medio al servicio de su autoconservación como ser vivo. La razón se convierte en un medio del hombre para garantizar y potenciar su autoconservación una vez, ante la incapacidad de aceptar la muerte, aquella se convierte en el núcleo de su autocomprensión. Ello va de la mano con la reducción de la naturaleza a ser una materia para la satisfacción de necesidades humanas que Schelling, con ironía, denunciaba en la concepción fichteana de la naturaleza ${ }^{23}$. Schelling describe así también, con el concepto del mal, la constitución de una racionalidad técnico-científica orientada al control y la explotación de la naturaleza.

La proliferación y lucha entre ideologías políticas y la expansión de la racionalidad técnico-científica son manifestaciones del mal, pero su manifestación más espectacular es -en el Freiheitschrift- el imperialismo. Los Estados-naciones son entidades particulares. Suponen un territorio y una cultura particulares. No obstante, la expansión potencialmente universal de esa particularidad, a través de la guerra, junto con la preservación de las conquistas a través de la coerción, es el mismo imperialismo. En los apartados del Freiheitschrift dedicados a la historia humana, su manifestación emblemática es Roma. En esa cronología figura como la fase en la cual "el principio que actuaba en el fundamento emergió finalmente como principio destinado a conquistar

\footnotetext{
${ }^{21}$ Schelling, Sämtliche Werke VII, 44.

${ }^{22}$ Marx y Engels, Ausgewählte Werke I, 240.

${ }^{23}$ Schelling, Sämtliche Werke VII, 18.
} 
el mundo, a someterlo todo y a fundar un reino mundial seguro y duradero" ${ }^{24}$. Roma es la forma de aparición del "mal general" en la historia.

Que, en el marco de su comprensión teológica de la historia, Schelling está aludiendo a su propio tiempo -esto es, al Imperio napoleónico- no es difícil de verificar. La identificación retrospectiva de la situación alemana frente a Napoleón, con la de los germanos frente a la antigua Roma, fue una idea de Fichte ${ }^{25}$. Hegel y Kleist se sirvieron también del paralelo entre Francia y Roma ${ }^{26}$. Kleist afirmaba, en una carta de 1806: "Nosotros somos los pueblos sometidos de los romanos" ${ }^{27}$. La comparación no era nada excepcional entre los intelectuales alemanes de la época.

Que Schelling hiciera ese paralelo tampoco es nada extraordinario. Más aún si se ve cómo, en su correspondencia, su comprensión del rol histórico de Napoleón equivale al rol histórico que tuvo Roma en la Antigüedad. A más tardar desde el "sistema del idealismo trascendental" (1800), Schelling atribuye a Roma el mérito de unificar pueblos, lenguas y costumbres mediante un mismo orden coercitivo, esto es, la búsqueda de un "Estado universal" 28 . "En el dominio mundial de Roma -podría decirse- el espíritu del mundo ha contemplado por vez primera la historia como universo" ${ }^{29}$. Con el Imperio romano surge por vez primera la idea de que la historia humana pertenece a un único "mundo" ${ }^{30}$ y que la pluralidad de los pueblos es solo la base para la unificación de la humanidad. Schelling le atribuye a Napoleón justamente esa tarea. En la carta a Windischmann, de, 8 de diciembre de 1806, sostiene lo siguiente:

...yo espero una completa reconciliación de todos los pueblos de Europa y, además, una relación común con el oriente; consciente o inconscientemente trabaja el triturador [Zermalmer] en esa dirección y está ya fuera de todos los límites en los que él, hasta ahora, se sostuvo. Esa unidad producida de la relación con oriente la considero yo el más grande problema en cuya resolución trabaja ahora el espíritu del mundo. ${ }^{31}$

${ }^{24}$ Ibid. VII, 379.

${ }^{25}$ Losurdo, Hegel und das Deutsche Erbe. Philosophie und nationale Frage zwischen Revolution und Reaktion, 41.

${ }^{26}$ Ibíd., 40-41.

${ }^{27}$ Ibíd.

${ }^{28}$ Schelling, Sämtliche Werke V, 291.

${ }^{29}$ Ibíd. V, 428.

${ }^{30}$ Ibíd.

${ }^{31}$ Schelling, Aus Schellings Leben in Briefen, 108. 
El "triturador" no es nadie distinto a Napoleón. Schelling lo denomina así pues ve en él una fuerza histórica que deshace el orden estatal europeo y demuele, además, como heredero de la ideología universalista de la Revolución Francesa, la validez de toda tradición nacional legal y toda cultura política puramente local. El Imperio napoleónico es, para Schelling, la forma contemporánea de Roma. Como el mal, en su configuración más concreta, no es una mentalidad que se extiende anónimamente, pues remite a los hombres como personalidades, Napoleón halla su puesto también en la historia como un genio del mal ${ }^{32}$. Él encarna, con su expansiva voluntad de dominación, el ansia de hallarse a sí mismo en todo ${ }^{33}$. En las "edades del mundo" pueden encontrarse también alusiones a esa condición centradas, por lo demás, en el carisma de Napoleón y, por tanto, en la fascinación demoniaca que ejercía sobre otros hombres ${ }^{34}$.

Si se comparan esos pasajes con las reflexiones de Goethe sobre el carácter de Napoleón pueden encontrarse afinidades. Así mismo, son interesantes los paralelos que resultan del hecho de que Goethe, como lo ha expuesto Hans Blumenberg, mitologizó la figura de Napoleón y la interpretó a partir de una antigua sentencia cuyo origen es discutido: "Nemo contra deus nisi deus ipse" ("Contra Dios solo un Dios") 35 . Napoleón, para Goethe, es -como se lo señala a Eckermann, el 11 de marzo de 1828una especie de "semidios". En la medida en que lo asocia a la figura mitológica de Prometeo $^{36}$, Napoleón figura como el héroe, de origen divino, que se rebela contra Dios, para traer la luz, las luces, al conjunto de los hombres. El debate en torno del sentido de la sentencia, entre H. Blumenberg y C. Schmitt, quien en su Teología política II la interpreta como una reflexión de "proveniencia cristológica" ${ }^{37}$ fundada en el

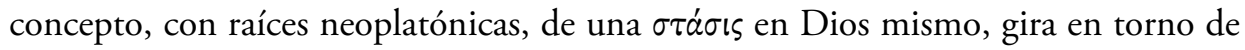
si ha de entenderse en sentido politeísta o monoteísta. Cuando se habla del Dios que combate a Dios, ¿se está hablando de dos dioses o de una división y revuelta ( $\sigma \tau \alpha \dot{\sigma} \sigma \varsigma)$ en Dios mismo?

Blumenberg anota correctamente que la lectura monoteísta de la sentencia, por parte de $\mathrm{Schmitt}^{38}$, tiene claros paralelos con la interpretación, por parte

\footnotetext{
${ }^{32}$ Tilliete, "Die Freiheitsschrift", 284.

${ }^{33}$ Carrasco, "1809: die Figur Napoleons und der Begriff des Bösen in der Freiheitsschrift", 74-75.

${ }^{34}$ Schelling, Die Weltalter. Fragmente. In der Urfassungen von 1811 und 1813, 93. Véase tembién a Schelling, Sämtliche Werke VII, 477.

${ }^{35}$ Ver a Blumenberg, Die Legitimität der Neuzeit.

${ }^{36}$ Appel, Johann Wolfang von Goethe: Ein Porträt, 271.

${ }^{37}$ Schmitt, Politische Theologie II. Die Legende der Erledigung jeder politischen Theorie, 123.

${ }^{38}$ Blumenberg y Schmitt, Briefwechsel 1971-1978 und weitere Materialen, 84.
} 
de Schelling, del mito de Prometeo. Para Schelling y para Schmitt, a juicio de Blumenberg, Prometeo simboliza la revuelta del hijo frente al padre sobre la base de que el hijo representa el descubrimiento del saber sobre-sí-mismo, del reconocimiento del valor incondicionado de la propia autonomía ${ }^{39}$.

Prometeo sirve así como modelo de la absolutización de la acción de un ser dependiente ontológicamente de otro, pero de tal modo que existe un parentesco entre aquel que se rebela y el poder desafiado: un parentesco entre poderes divinos interpretable en términos trinitarios.

Más allá de qué tan es acertada esa lectura de la sentencia "Nemo contra deus nisi deus ipse", las resonancias de su lectura por parte de Goethe y Schmitt iluminan la dimensión política de la idea del Dios dividido internamente del Freiheitschrift. Más allá de si existió o no alguna comunicación entre Goethe y Schelling al respecto, y del hecho de que la sentencia sea abordada, además, por dos autores definitivos en la composición del texto -a saber, Lutero en De servo arbitrio y Jakob Böhme- existe afinidad estructural entra la sentencia teológica referida a Napoleón-Prometeo y la idea de Schelling del Dios internamente dividido, por más de que aquel no se ha leído aquí, trinitariamente, como el Hijo. En este entramado de referencias es de anotar también que Goethe asoció la figura histórica de Napoleón con el accionismo del ego absoluto en Fichte ${ }^{40}$ y que, en el Freiheitschrift, como ya se vio, Fichte representa la lectura, en clave filosófica, de la mentalidad de los individuos modernos. La interpretación de Napoleón como una personificación del mal que se alza, en Dios mismo, contra Dios, no resulta arriesgada bajo esos supuestos.

Si esto es correcto y el "mal general" es la base para la creación de un reino cristiano, puede entenderse cuál es la función que le asigna Schelling al imperio napoleónico. En la correspondencia con Windischmann, resulta claro que Schelling ni simpatiza con la resistencia nacionalista a Napoleón representada por Fichte, ni simpatiza con el proyecto conservador de la Restauración, al cual se habían adherido intelectuales como F. Schlegel. Schelling, sin dejar de lamentar el efecto destructivo de la guerra, saluda la obra del 'triturador' porque sus acciones son el presagio de una renovación histórica: "Y sin embargo siento yo profundamente el carácter incurable del tiempo y prosigo alegrándome de la demolición" "11; "la revolución ha comenzado solo hasta ahora en Alemania; yo considero ciertamente que ha llegado el espacio para un nuevo mundo (7.01.1807)". Schelling no ve en el Imperio napoleónico un punto de

\footnotetext{
${ }^{39}$ Schelling, Sämtliche Werke VII, 1; 482.

${ }^{40}$ Schmitt, Politische Theologie II. Die Legende der Erledigung jeder politischen Theorie, 122.

${ }^{41}$ Schelling, Aus Schellings Leben in Briefen, 108.
} 
llegada de la historia, pero sí un proceso de destrucción necesario para el surgimiento de una fase superior. Dice Schelling en el Freiheitschrift:

Pero, así como este [el fundamento que actúa en la naturaleza] permanece eternamente como fundamento sin ser él mismo, del mismo modo el mal no puede alcanzar la realidad efectiva, y solo sirve de fundamento para que el bien formándose a partir de él mediante sus propias fuerzas, sea -gracias a su fundamento- un ser independiente y separado de Dios en donde este último se posea y se reconozca a sí mismo. ${ }^{42}$

Si el Imperio es una forma del mal y la superación del mal es el "nuevo reino", la Iglesia cristiana universal, la obra de Napoleón -por más destructiva que pueda ser respecto a Estados nacionales singulares- tiene la función histórica de preparar y anticipar la llegada del fin de la historia por la vía de una constitución de un orden político tendencialmente global. El Imperio es de nuevo un signo del nuevo reino y por eso es bienvenido, "pues reino es una unidad” ${ }^{43}$. El Imperio prefigura la verdadera unidad, pero, justamente por ser el producto de una empresa militar, basado en la fuerza, no logra nunca constituirla ${ }^{44}$.

Schelling, desde ese marco, no censura, como los nacionalistas, la formación de un orden primero paneuropeo -global a mediano plazo-porque es una precondición de la constitución de un reino cristiano, o sea, del sumo bien político. La meta de la historia es el "nuevo reino" y todo lo que aparezca antes de él solo es un punto de tránsito hacia ese estado. Si lo propio del Imperio es el universalismo, Schelling lo ve como una fase previa a la posible constitución de una comunidad no coercitiva, fundada exclusivamente, como Gesinnungsgemeinschaft, en las creencias, gracias a la cual podrá ser alcanzada una paz definitiva. Las guerras derivadas del proceso de expansión del Imperio son el caos, propio del fundamento, requerido para que el deseo de unidad de la humanidad se vivifique y avance. Schelling puede decir, como lo hace Novalis en De Europa o la cristiandad, lo siguiente: “...una verdadera anarquía es el elemento generador de la religión. De la destrucción de todo lo posible, levanta esta su cabeza cual nueva creadora del mundo" ${ }^{45}$.

\footnotetext{
${ }^{42}$ Schelling, Sämtliche Werke II, 378.

${ }^{43}$ Ibid. II, 460.

${ }^{44}$ Ibid.

${ }^{45}$ Novalis, Die Christenheit oder Europa, 510.
} 


\section{Lo histórico-político en clave ontoteológica}

Como lo político pertenece al reino de la historia, y la historia solo se deja pensar metafísicamente, únicamente se puede comprenderlo desde categorías metafísicas. No hay una "ciencia" o una filosofía política. Lo político, como el ámbito de la vida humana en común, es modalidad de lo que es. La metafísica tiene como presupuesto la conciencia de la totalidad en su forma "compacta" ${ }^{46}$. La conciencia inmediata de Dios, o sea, la intuición de la totalidad es, en últimas, la razón humana misma ${ }^{47}$. La tarea de la metafísica es articularla y desplegarla conceptualmente con la ayuda del entendimiento $^{48}$. La tarea del entendimiento, entonces, es diferenciar conceptual y dialécticamente las articulaciones internas de una intuición de la totalidad.

En la medida en que, en el Freiheitschrift, se define el ser como "querer" (Wollen), esas diferenciaciones conceptuales de la intuición de la totalidad son también diferenciaciones internas del "querer". Dios mismo es un querer. Que el ser sea querer muestra, sin embargo, a la vez, los límites de una metafísica como forma de conocimiento basada exclusivamente en el trabajo del entendimiento. El ser se deja comprender mediante él, pero este conocimiento no constituye una condición suficiente. Hay -como se verá- un componente volitivo en la comprensión misma del ser que empalma la descripción metafísica de lo histórico-político con la participación del individuo concreto en él. Desde el punto de vista del entendimiento se puede pensar el ser, en primer lugar, desde la estructura del lenguaje y, en segundo lugar, desde la dialéctica entre los conceptos de existencia y fundamento.

1. Schelling piensa el ser desde la estructura del juicio (Urteil) y, por tanto, desde el lenguaje proposicional. En el juicio, por tanto, los predicados no son abstracciones de la mente de un sujeto atribuidas accidentalmente a tal o cual entidad en el mundo "externo" sino son la expresión de las propiedades de la cosa misma, en cuanto tales propiedades la diferencian de otras cosas y las muestran en su máximo despliegue. Si se dice, por ejemplo, "el hombre es racional", el predicado racional es algo que le pertenece intrínsecamente al sujeto, al hombre, y que expresa lo en él que actualiza plenamente sus posibilidades. Una predicación conforme al ser de las cosas está sujeta así a la condición de dar cuenta de qué es propiamente algo y en qué alcanza su actualización. El juicio muestra la copertenencia de sujeto y predicado. La "identidad" es tanto la diferencia de ambos, pues remiten a dimensiones ontológicamente diferentes, como su unidad y dependencia recíproca. La cópula, en el juicio, tiene

\footnotetext{
${ }^{46}$ Voegelin, The Collected Works of Eric Voegelin. Vol 17: Order and History. IV: The Ecumenic Age, 233.

${ }^{47}$ Schelling, Sämtliche Werke VII, 149.

${ }^{48}$ Ibíd. VII, 415.
} 
ambas funciones. Es un tercer elemento que hace explícita la separación de sujeto y predicado; pero es también aquello que los une. El "es" del juicio muestra así cómo el ser, en sí mismo, es la unidad de lo diferente.

La "identidad" no es, para Schelling, tautológica y no informativa, como en principio podría parecer la fórmula $\mathrm{A}=\mathrm{A}$. La identidad es una relación entre elementos conceptualmente diferenciables $(\mathrm{A} \neq \mathrm{B})$ que, sin embargo, expresan una misma cosa. Desde este punto de vista, el ser, en Schelling, no es pensado en términos "existenciales" (el puro que [dass] del sujeto) ni en términos puramente esencialistas (el puro qué del predicado) sino como la unidad, y el tránsito, requerido de tiempo, entre esas dos diferentes dimensiones. Ni el sujeto solo ni el predicado solo son lo que propiamente es. Esto solo lo es aquello mismo que se expresa replegado en tanto sujeto y, desplegado, en tanto predicado, pero trasciende a ambos como a sus propias determinaciones. El "es", la cópula, no es solo lo que hace posible el tránsito entre sujeto y predicado sino es aquello sin lo cual ambos no serían posibles. Es como si se dijera: "hay algo que es hombre (en un cierto sentido)" y "hay algo que es racional" (en un cierto sentido). El "ser-hombre" y el "ser-racional" son, en forma similar al uso, en Frege, del concepto de "sentido" (Sinn), modos de presentación de lo mismo ${ }^{49}$.

2. Dios es único, pero en él se pueden diferenciar distintas dimensiones, las cuales son isomorfas con las distintas funciones presentes en un juicio. Los principios en los cuales se diferencia son el "fundamento", la "existencia” y el "espíritu". En términos de categorías con larga trayectoria en la historia de la metafísica -a las cuales Schelling mismo recurre en el Freiheitschrift-, las dos primeras corresponden, grosso modo, a potencia y acto, o a materia y forma, respectivamente. Si bien estos conceptos son redefinidos al ser integrados en la dialéctica de fundamento y existencia, ellos constituyen el trasfondo histórico de esta distinción. El espíritu, en ese marco, es aquí aquel tercer elemento que no es uno con el fundamento y la existencia pero que se expresa, como actividad unitaria, a través de ambos. Schelling, en ese sentido y sobre la base de una postura (pan)teísta ${ }^{50}$, desarrolla un particular hilemorfismo. Pensar el ser es, por tanto,

${ }^{49}$ Lütterfelds, Das Erklärungsparadigma der Dialektik. Zur Struktur und Aktualität der Denkform Helgels, 27.

${ }^{50}$ En el marco de su polémica con F. Schlegel, Schelling se opone al panteísmo entendido como una doctrina sobre Dios en la cual este es una entidad impersonal en la que se disuelve toda particularidad y en la cual, desde una postura determinista (vía "fatalismo"), se niega toda libertad humana. Desde una posición teísta plantea, en contraposición, que Dios debe ser pensado antropomórficamente -como "personalidad" - y considera además la singularidad ontológica de la persona humana como ser libre. Esto fue interpretado, en su época, como una reacción cristiana al spinozismo (Schneider, Persönlichkeit und Wirklichkeit. Nachidealistische Schellingrezeption bei Immanuel Hermann Fichte und Christian Hermann Weiße, 81). Sin embargo, Schelling no se opone al panteísmo en cuanto ontología en la cual la 
recurrir a una dicotomía conceptual que, en sus relaciones múltiples, acumulativas y cada vez más complejas, puede dar cuenta de todos los tipos de fenómenos posibles en el reino de la naturaleza y en el de la historia.

Como esas dos categorías adquieren distintos sentidos según el momento en que intervengan, es imposible definirlas con abstracción del momento de la construcción conceptual del ser en que aparezcan. No obstante, puede decirse, para rescatar algunas propiedades esenciales, que el "fundamento" es una "voluntad de revelación”, o sea, el punto de partida para que emerja algo cualitativamente diferente y, sobre todo, algo ya determinado. El fundamento se aproxima al concepto de materia y al de potencia debido a su indeterminación, pues es aquello que puede adoptar distintas formas o configuraciones en acto. Cuando una entidad surge o sale de ese estado de indeterminación se puede hablar en consecuencia de su existencia, pues ex-sistere es ponerse fuera, salir de un estado de incubación y retraimiento.

La existencia es el ser de Dios en cuanto lo potencial ha sido dejado atrás por una forma estable y la ausencia de dirección de las fuerzas materiales se ha cristalizado en una entidad identificable. No hay, sin embargo, existencia desligada del fundamento, así como tampoco es posible este último sin relación con la existencia. La existencia no es el fundamento, tal como el predicado no es el sujeto, pero lo presupone. La existencia es el ser como determinación y limitación que, sin embargo, una vez prosigue el proceso que es la creación, se puede tornar de nuevo en fundamento al impedir, por su ensimismamiento, que surja de él un nuevo nivel ontológico. La creación es el proceso histórico mediante el cual Dios, como espíritu, produce progresiva y acumulativamente nuevas mediaciones de forma y materia, de existencia y fundamento, $y$, de esta manera, se produce simultáneamente a sí mismo.

Desde este doble punto de vista, decir de lo histórico-político que "es" significa en primer lugar que puede distinguirse en ese dominio algo en la función de sujeto y algo en la de predicado, y que entre ambos momentos, pensados como "identidad", tiene lugar un tránsito. Decirlo supone, en segundo lugar, que hay una "materia" sociopolítica, la cual, con mediación de la actividad de una entidad superior, se une progresivamente con cierta "forma". Como la una y la otra son momentos de una misma entidad, el producto de esa mediación es la misma automediación de esa entidad superior: Dios como "espíritu".

pluralidad de las cosas está contenida en Dios, sin perder por ello una relativa autosuficiencia en la cual la libertad humana es expresión privilegiada de la omnipresente libertad divina. Desde ese punto de vista, Schelling considera el panteísmo como una postura ontológica inevitable para la razón (Schelling, Sämtliche Werke VII, 339). En consecuencia, puede designarse su posición, en el Freiheitschrift, como "(pan)teísmo". 
Lo político, en consecuencia, debe pensarse como una modalidad del proceso creador mediante el cual Dios le da, a lo largo del tiempo y, por tanto, históricamente, una forma a su "propia" y resistente materialidad. La historia humana, tal como Schelling la concibe, está así dividida en dos períodos:

- En el primero, correspondiente grosso modo al "ansia" (Sehnsucht) en la filosofía de la naturaleza, hay un impulso constante de unidad, de creación de un orden estructurado que nunca se consuma plenamente y se mueve, por tanto, cíclicamente ${ }^{51}$. El fundamento contiene, tanto en la naturaleza como en la historia, "la totalidad del ser divino, pero no como unidad"s2. Ese periodo es la básicamente el de las civilizaciones precristianas y se divide, a su vez, en un período prehistórico (la "edad dorada del mundo"), las primeras culturas sedentarias (Persia, Egipto y Babilonia) y la Antigüedad clásica: Grecia y Roma. Todo esto constituye, sin embargo, el sujeto y la materia del desarrollo histórico.

- $\quad$ El límite entre el primer y el segundo periodo es la personificación del logos: la aparición de Cristo. A él le sucede la descomposición del Imperio romano como fenómeno paralelo a la formación de una pluralidad de pueblos con múltiples lenguas y el proceso, aún en un curso, de restaurar, sobre la base del declive del Imperio, la unidad de la humanidad bajo la forma de un "nuevo reino"s3. A ese periodo pertenece la evangelización iniciada por los apóstoles, las Cruzadas, la labor de los misioneros en el continente americano ${ }^{54}$.

Solo con el cristianismo aparece la posibilidad de un avance lineal y verdaderamente universal de la historia y, con ella, la posibilidad de una suerte de progreso para toda la humanidad. El "reino" anunciado por Cristo es la 'forma' que, por la misma acción divina de Dios como espíritu, se va abriendo paso en medio de una serie de intentos fallidos, de carácter estatal, por instaurar una comunidad humana genuinamente universal. La existencia, en el sentido histórico-político, es aquella unidad estable que va saliendo a luz, progresivamente, de formas de organización colectiva particularistas y, a pesar de su larga duración, pasajeras. Pensar desde la razón es pensar en el horizonte de la totalidad. Pasando por quiebres y conflictos, y sin necesidad de eliminar toda particularidad, surge así, paulatinamente, una comunidad global.

Ahora bien, todo esto se deja afirmar exclusivamente desde la perspectiva del entendimiento, pero el ser, como "voluntad", no es solo comprensible conceptualmente.

\footnotetext{
${ }^{51}$ Žižek, The Indivisible Remainder. An Essay on Schelling and Related Matters, 42.

52 Schelling, Sämtliche Werke VII, 378.

${ }^{53}$ Ibid. VII, 380.

${ }^{54}$ Schelling, Sämtliche Werke V, 435.
} 
Para entender mejor esto es preciso hacer una suerte de arqueología del "espíritu" y remontarse, por la vía de una teogonía, a la fase previa a su constitución. En ese marco aparece el bivalente concepto de "indiferencia". Esta es en principio la relación prereflexiva y meramente sincrónica -no diacrónica como la creación- entre fundamento y existencia. Aquí Dios no se ha hecho aún consciente de sí mismo y solo es el protofundamento (Urgrund) desde el cual todo podría surgir. Aquí los dos principios coexisten sin oposición y sin mediación. Es solo como reacción a la tendencia de uno de los polos, el fundamento, a absorber en sí la relación como tal que se constituye Dios como espíritu y emerge entonces como tal lo que funda la relación. En ese momento empieza a haber un querer, pero hasta entonces solo hay una coexistencia de los opuestos, en cuanto elementos, ambos, meramente potenciales, que se capta volitivamente como "indecisión" (Unentschiedenheit).

No obstante, la "indiferencia" tiene un segundo sentido. Ella es también la absoluta falta de diferencia, o sea, la no-diferencia, pero no entendida como negación de una diferencia previa ni tampoco como no-relación entre términos opuestos. Lo primero supondría la precedencia de la dualidad. Lo segundo es el mismo primer sentido de la "indiferencia". La indiferencia, ahora como no-fundamento (Ungrund), es más bien lo absolutamente Uno desde lo cual surge (como causa sui) el protofundamento.

El no-fundamento no puede ser strictu sensu un origen. Su nombre lo dice: no fundamenta nada, no es principio de nada, no está relacionado con nada. Es lo absoluto como pura unicidad cuya naturaleza no puede ser reproducida por la estructura (dual) del juicio. Se trata de un concepto límite cuya comprensión aproximada, aparte de la negación de todas las diferencias con las cuales el pensamiento opera habitualmente, ocurre en términos volitivos: como la voluntad absolutamente vacía; ya no la voluntad indecisa, propia de la indiferencia como "disyunción" de los principios, sino la voluntad que no ha pasado al acto, que no tiene ningún fin, que carece de cualquier orientación hacia la autodeterminación. Schelling, con variaciones importantes y a veces entremezclándola con el Urgrund, hará referencia a ella, en Las edades del mundo, como la "voluntad que nada quiere"55. El no-fundamento, al encontrarse más acá de las herramientas del entendimiento -a saber, el análisis del juicio y las categorías basales de fundamento y existencia- escapa a sus posibilidades de conceptualización. El ser se comprende prácticamente bajo distintas modalidades volitivas como "ansia", "indecisión", "elección" o "resolución". Hasta ese punto tales estados volitivos sintonizan al ser humano con el ser, pero no por ello eliminan la cognición, pues el querer implica siempre una dimensión conceptual.

\footnotetext{
${ }^{55}$ Schelling, Die Weltalter. Fragmente. In der Urfassungen von 1811 und 1813, I 27,28. 15.
} 
El no-fundamento, sin embargo, no es propiamente un concepto. Es más bien, desde un punto de vista epistemológico, el remanente de la negación de toda conceptualidad. No hace más que señalar hacia el límite del entendimiento y de la razón misma (pues el Ungrund no es ninguna totalidad). Ese más allá de todo no explica nada sino es el límite de toda explicación. Tiene así el estatuto de términos paradójicos como lo "inefable". No por ello el no-fundamento deja de ser parte de una comprensión del Ser (si por Ser se entiende también algo más allá de la presencia y el fundamento). La inacción previa a la constitución de todo, del mundo, de Dios mismo como agente, señalada por el término "no-fundamento", solo se puede captar aproximativamente mediante una experiencia volitiva. El Ungrund no es, por supuesto, nada psicológico, pues es aquello que subyace a la existencia misma de Dios, pero solo se puede captar, más allá de todo concepto, como el estado de la voluntad previo no solo a todo querer sino a toda posibilidad de elección y a todo fin.

El Ungrund tiene implicaciones a la hora de pensar la política. Schelling piensa las comunidades humanas mediante dos instituciones posibles: el Estado y la Iglesia. Toda institución es una forma de coordinación estable de la actividad de diversos agentes, una forma de unificación de la acción humana. El Estado es una forma de coordinación centrada en los efectos disuasivos de la coerción, cuyo radio de acción siempre es local. La iglesia, por su parte, es una forma de coordinación centrada en el libre asentimiento propio de la $\mathrm{fe}^{56}$, cuyo radio de acción es tendencialmente universal. Schelling piensa la Iglesia en el marco del monoteísmo cristiano. El sumo bien político es la constitución de una institución totalmente libre de dominación con reconocimiento global y Schelling, confiando en que solo el monoteísmo cristiano está en capacidad de alcanzar esa meta histórica, cree que la llegada del sumo bien político, el "nuevo reino" ${ }^{77}$, solo es posible mediante una cristianización de la humanidad. "La verdadera unidad solo es alcanzable por una vía religiosa"58. La Iglesia puede tener ciertamente como base o fundamento a los estados nacionales (y las relaciones entre ellos) pero tiende a desintensificar o desvanecer la lealtad de los individuos hacia ellos. Como dice Brata Das:

Esta teología política es una teología política negativa: en el desierto de religión, todas las soberanías (que existen en el nombre de su poder y fuerza)

\footnotetext{
${ }^{56}$ Schelling, Sämtliche Werke VII, 464.

${ }^{57}$ Ibid. VII, 380.

${ }^{58}$ Ibid. VII, 464.
} 
están sumergidas, y nuestra finita existencia es, de este modo, liberada de todas las 'obligaciones normativas' de potencias mundanas. ${ }^{59}$

Solo una Gesinnungsgemeinschaft puede satisfacer el interés de los individuos en forma de unidad que abarque a todos los seres humanos posibles: los pasados, los presentes y los futuros. El mal introduce, como imperialismo, un desarreglo en la jerarquía de las instituciones: pone al Estado (algo particular) en el lugar de la Iglesia (lo universal).

El imperialismo es la expansión del modo de coordinación de la acción propio del Estado-nación a un nivel universal; pero aun la superación progresiva del mal por la vía del "reino", presupone una ontología basada en la distinción fundamentoexistencia, o sea, el dualismo interno a Dios. El no-fundamento, por el contrario, escapa a esa dualidad y es lo Uno mismo. La misma elección entre el bien y el mal supone un dualismo de principios. El reino es aún una relación entre el fundamento (la pluralidad de los estados) y la existencia (la comunidad única fundada en convicciones religiosas) que mantiene la estructura propia del "espíritu" y, en esa medida, no es la suprema unidad.

La noción de acción implicada en el "querer" es el esfuerzo para la consecución de un fin representable, a costa de la exclusión de otro principio, pero en la esfera previa al "querer", que es el no-fundamento, no hay ningún contenido conceptualmente precisable. La acción divina para crear el "nuevo reino" no pertenece por eso a la esfera del no-fundamento. De ahí que esa indeterminación radical, apenas nombrable ${ }^{60}$, solo se deje interpretar teológicamente como aquella propia de la espontaneidad incausada del "amor" (cristiano) ${ }^{61}$.

Ese amor, que es la unidad pura ${ }^{62}$, es la posibilidad aún vacía de dar lugar a algo que escapa por completo a la acción humana y no es conceptualmente comprensible. De ese modo, el no-fundamento, a nivel político, funciona -en términos de E. Peterson- como una suerte de "reserva escatológica" ${ }^{63}$ que mantiene abierta una cierta incertidumbre sobre el fin último de la historia. Esto vale como antídoto frente a los utopismos de las diversas ideologías humanistas -incluyendo, en la obra tardía de Schelling, el comunismo-, pero también contra la meta de la filosofía de la historia diseñada por el mismo Schelling.

\footnotetext{
${ }^{59}$ Das, The Political Theology of Schelling, 110.

${ }^{60}$ Schelling, Sämtliche Werke VII, 406.

${ }^{61}$ Ver a Nygren, Eros und Agape. Gestaltwandlungen der christlichen Liebe.

${ }^{62}$ Schelling, Sämtliche Werke VII, 406-408.

${ }^{63}$ Anglet, Der eschatologische Vorbehalt. Eine Denkfigur Erik Petersons, 19-40.
} 
Eso no significa que el hombre moralmente responsable abandone su interés para actuar conforme a la idea del reino, pues el no-fundamento está más allá del bien y del mal y no sirve, de ninguna manera, de orientación moral. La actividad humana, incluyendo aquella comprendida en el mal, es constitutiva del devenir de Dios. Dios es acción y el ser humano solo es propiamente parte de Dios en tanto agente. La acción humana es así parte del devenir de Dios y, por tanto, del reino. La voluntad irresoluta no puede ayudar a constituirlo. El único bien (meta)político posible es la Iglesia universal y el no-fundamento solo constituye una forma de no-saber, una especie de docta ignorancia para quienes hayan transitado hasta sus límites el camino de la metafísica, gracias a la cual el hombre reconoce los límites últimos de todos sus proyectos políticos. Como el no-fundamento no puede indicar de ninguna manera qué se debe hacer, bien puede adoptarse frente a él una sentencia luterana con raíces socráticas: quae supra nos, nibil ad nos (lo que nos rebasa no nos concierne).

Para el creyente tendrá, sin embargo, un efecto colateral: saber que su acción puede refrenar el mal y contener su expansión; pero saber también que esa lucha espiritual no es tal vez la resolución definitiva de los conflictos históricos porque esa resolución definitiva es un enigma. Tampoco el cristiano sabe verdaderamente del fin último de la historia. El bien que representa la Iglesia sería la contención del mal, pero ni siquiera la Iglesia misma podría atribuirse a sí misma la condición de ser el fin de la historia. Esa es una incógnita más allá de la razón y el entendimiento humano y, por tanto, de las mismas posibilidades cognitivas de la metafísica como teología.

\section{Dimensiones del conocimiento teológico}

La teología no es para Schelling, junto con la cosmología especulativa y la doctrina del alma, un momento de la metaphysica specialis. Dios es el summum ens, de modo que conocerlo, tanto en su estructura fundamental (sincrónica) como en su despliegue (diacrónico), es conocer todo-lo-que-es. De ese modo, el conocimiento de la naturaleza y el de la historia es uno con el conocimiento de Dios. El saber que trasciende la división del trabajo científico entre ciencias de la naturaleza y del espíritu, y cuyo objeto es la totalidad, bien podría denominarse así teología. ¿Qué significa, desde ese punto de vista, conocer? Por un lado, producir una construcción especulativa de la totalidad que explique su devenir a partir de la determinación de sus principios esenciales y de las relaciones entre esos principios. Los conceptos asociados a esos principios son $a$ priori y, al modo de un axioma, no se dejan fundamentar, pero se validan a posteriori en cuanto permiten construir, bajo la forma de un sistema, un "modelo" de los fenómenos fundamentales contenidos en la totalidad. 
Por otra parte, a modo de una hermenéutica de la existencia, el conocimiento consiste, para el individuo, en la elaboración de una comprensión de sí mismo en vista de la totalidad que se funda en ciertas vivencias fundamentales: la angustia (ante la muerte), la libertad de elección, la indecisión, el deseo de unidad que es el amor humano. Pensar metafísicamente presupone, a la par que un ejercicio intelectual, una serie de estados anímicos, los cuales no solo impulsan ese ejercicio, sino son el medio en el cual mantiene su sentido y su inteligibilidad, el compendio de ambas cosas es lo que Voegelin llamaría una "experiencia noética" ${ }^{64}$. Desde este punto de vista -que liga a Schelling con Spinoza- la ontoteología nunca deja de tener una relevancia práctica y apunta, en últimas, a impulsar cierta actitud ética.

Las dos dimensiones del conocimiento no están yuxtapuestas, pues -por una parte- el conocimiento de la totalidad no puede dejar de incluir al ser humano, ya que un conocimiento de todo-lo-que-es no puede omitir la singularidad de la existencia humana; por otra parte, el conocimiento de la totalidad presupone la pretensión del ser humano de comprenderse a sí mismo a la luz, no de un procedimiento introspectivo ni tampoco de su condición biológica o histórico-social, sino a la luz de su posición en la totalidad. La (onto)teología, desde ese punto de vista, supone tanto un trabajo constructivo del pensamiento como un proceso de autocomprensión que requiere, justamente, del ejercicio de descentramiento alcanzado por el pensamiento especulativo. La metafísica como teología, por eso mismo, no es una teoría de lo-que-es en abstracto, desligada del que comprende, pues consiste en una experiencia intelectual mediante la cual el ser humano se aclara, de manera progresiva, su propio ser. La metafísica, como tipo de teoría, no se acredita solo por qué tan consistentes y exhaustivos son sus principios sino porque motiva una transfiguración de la autocomprensión de quien reproduce en sí mismo sus pasos. En ese sentido, Schelling es heredero de la concepción de la filosofía como una forma de "espiritualidad".

El conocimiento teológico, sin embargo, tiene una tercera dimensión. Schelling ha renunciado a una filosofía de la reflexión en la cual el sujeto, mediante operaciones intelectuales de distinta complejidad, es el contenido y la forma del conocimiento. El ser humano no es la razón desde la cual se "pone" todo lo objetivo sino es, más bien, algo ya puesto en el curso de un proceso natural e histórico. Conocerse no es un proceso puramente introspectivo, pues supone, más bien, conocer el desarrollo natural e histórico en el que uno está involucrado. Y esto, para Schelling, en su fusión de pensamiento especulativo y cristianismo, supone situarse en el proceso de despliegue del Dios cristiano, situarse en un momento de la teodicea. De ese modo, la

${ }^{64}$ Voegelin, Die neue Wissenschaft der Politik. Eine Einführung, 77. 
hermenéutica existencial no solo es, para Schelling, una "reflexión ontológica” acerca de quién es uno a la luz del todo, sino es también -para decirlo con Paul Ricoeuruna "reflexión concreta": una apropiación personal de los marcos simbólicos situados históricamente en los cuales el individuo ya está envuelto ${ }^{65}$. Conforme a esto, un momento del conocimiento teológico es comprenderse a sí mismo en el marco de la narrativa histórica ofrecida por el cristianismo, porque esta es la tradición en la que recae la inteligibilidad de la historia.

Más allá de qué tan arbitraria y eurocéntrica es esta suposición, lo fundamental es que Schelling no aísla la comprensión de sí mismo de la comprensión de grandes marcos culturales pues estos marcos son las mismas cristalizaciones temporales de la historicidad divina. El conocimiento teológico-político se compone así de una dimensión especulativo-racional, de una dimensión hermenéutico-existencial y de una reflexión concreta ligada a esta última, pues las vivencias fundamentales de la existencia humana están articuladas en un lenguaje y una visión de mundo cristianas. El conocimiento propio de la metafísica es así, también, un desciframiento, existencialmente significativo, de la tradición religiosa. Conocer a Dios es interpretar su mensaje, hacer propio su contenido soteriológico, participar como intérprete de ese marco de sentido histórico instituido por la palabra revelada. La ontoteología no es, por tanto, puramente especulativa-racional, pues supone también -en una relación tensa con lo anterior- una hermenéutica de la Palabra sagrada. A Dios no se lo conoce solo mediante conceptos como "fundamento", "existencia" o "indiferencia". Interpretar el sentido de símbolos como los de "pecado" o "creación" es parte de su adecuada comprensión. Interpretar existencialmente esos símbolos, cuyo sentido no se deja definir unívocamente, es parte del conocimiento de Dios. Más aún cuando se añade el elemento volitivo que es constitutivo de la identidad personal.

El Freiheitschrift redescribe, en términos conceptuales y metafóricos, la situación histórico-cultural para poner a su lector ante un dilema: reflexionar sobre la elección entre el bien y el mal y, en esa medida, dado que estos no están referidos a acciones puntuales, sobre su propia identidad. La "religiosidad", como elección del bien, es la reconstitución consciente del individuo en tanto "personalidad". La tarea política de la filosofía, desde ese punto de vista, es retrotraer los fenómenos históricos de larga duración al escenario de las vivencias fundamentales en el marco simbólico de una tradición religiosa y con el propósito de impulsar una decisión. Esa decisión es personal e inalienable, pero para todos los que la realicen tiene una connotación política: su adhesión a un mismo horizonte comunitario.

\footnotetext{
${ }^{65}$ Ricoeur, El conflicto de las interpretaciones. Ensayos de hermenéutica, 240.
} 
De ese modo, solo hay una decisión políticamente determinante: aquella en torno a la cual elijo quién quiero ser. No hay decisiones políticas, junto a decisiones éticas, religiosas o económicas. Elegir quién quiere ser uno es transversal a cualquier diferenciación de campos de acción. O bien uno elige existir en tanto "personalidad", y eso es uno con la "religiosidad", o bien uno elige conservar la subordinación de la personalidad a la "mismidad" (el mal). Cualquiera de las dos opciones releva al individuo de tomar decisiones exclusivamente políticas, pues todas las razones que puedan operan en un ámbito específico suponen una suerte de metapreferencia o de deseo de segundo orden.

Resolverse por una opción no es reflexionar, de situación en situación, cómo actúa uno. Las acciones singulares presuponen una elección de quién quiere uno ser. Operatio sequitur esse. La elección de la personalidad consiste en subordinar libremente la propia naturaleza y la propia agencia al marco más ampliamente pensable de universalidad. Dios es el todo, de modo que pensar desde Dios es pensarse desde la totalidad. La decisión define cómo uno se relaciona consigo y no qué es lo relacionado. Sobre eso el decisor no tiene control. No obstante, decidirse por la supremacía de la "voluntad general" sobre la mismidad, o sea, ser una "personalidad", alinea al individuo concreto con la perspectiva de la totalidad bajo la forma de una teodicea dirigida a la instauración del "reino". El conocimiento, en ese sentido, no es políticamente neutral: ni los estados-nación, ni institución alguna basada en medios coercitivos, pueden aspirar al rol del genuino bien común, incluso si se reconoce, en un mundo de pecadores, su necesidad temporal ${ }^{66}$. La perspectiva de la razón no puede ser sino universalista y libre de toda coerción.

\section{Conclusión}

La teología política es, en Schelling, una forma de teoría, o sea, de visión de la totalidad de lo que es (en cuanto Dios es el summum ens) en parte especulativo-conceptual y en parte histórico-simbólica, que está indisolublemente ligada, como una hermenéutica existencial, a la autocomprensión del individuo, mediante la cual se busca, simultáneamente, una recomposición de la vida en común. La teología política de Schelling apunta así a reconfigurar, contra los órdenes políticos seculares, el horizonte y la escala de la vida en común, mediante una apelación, simbólicamente mediada, especulativamente validada y existencialmente significativa, a una redefinición contingente de la identidad personal.

${ }^{66}$ Hollerbach, Der Rechstgedanke bei Schelling. Quellen-Studie zu seiner Rechts- und Staatsphilosophie, 195-196; Carrasco, "1809: die Figur Napoleons und der Begriff des Bösen in der Freiheitsschrift", 77-78. 
La decisión de quién es uno no se deja abstraer aquí del tipo de comunidad en la que uno participa, pues el compromiso religioso, no de modo directo, pero sí con la mediación de la relación con Dios, lo pone a uno en un plano de relación con los otros en el cual se comparte una temporalidad y una finalidad moral. Quien se define como personalidad ya no se puede comprender meramente como ciudadano de un Estado-nación; tampoco como miembro de un imperio en el cual un mismo Estado, cuya naturaleza es inevitablemente coercitiva, absorbe una pluralidad de naciones. Lo suyo es el "nuevo reino", o sea, una comunidad universal, supranacional, libre de dominación. En la medida en que esto no se cristaliza en ninguna iglesia visible, su efecto primordial es una reserva interior frente al estatismo, el nacionalismo y el imperialismo, acompañada por una esperanza universalizable.

Si se piensa la teología política de Schelling en diálogo con la matriz de los debates contemporáneos sobre el tema, a saber, el texto de 1922 de Carl Schmitt con esta misma denominación ${ }^{67}$, la postura planteada en el Freiheitschrift tiene importantes puntos de congruencia, pero también significativas diferencias.

Schmitt entiende la teología política como una (meta)teoría de los fundamentos teológicos del pensamiento político moderno subyacentes a la lucha ideológica de una coyuntura política específica, que convoca simultáneamente a un compromiso existencial total orientado a salvar su validez contra el encubrimiento y desfiguración de tales fundamentos que es la misma secularización. Se trata, a la vez, de una "sociología de los conceptos" y de una doctrina apelativa ${ }^{68}$ que apunta a fundar la acción política en fundamentos incondicionales ${ }^{69}$. Aunque en Schelling no hay, por supuesto, nada en la línea de una historia de los conceptos, su teología política también presenta el conjunto de la cultura moderna como una absolutización de fines mundanos que no logra nunca desprenderse de la incondicionalidad del pensamiento religioso cristiano y, en esa medida, no es genuinamente autosuficiente. Con esto también desenmascara teóricamente los presupuestos religiosos del antropocentrismo moderno y prescribe, como antídoto, un retorno a una experiencia cristiana del mundo y de la historia que no es una simple restauración, pues tiene como base o fundamento las instituciones y formas de producción modernas, pero que, como en Schmitt, se opone prácticamente a los movimientos políticos secularistas y, en particular, a los movimientos socialistas.

\footnotetext{
${ }^{67}$ Ver a Schmitt, Politische Theologie. Vier Kapitel zur Lehre von der Souveränität.

${ }^{68}$ Böckenförde, "Politische Theorie und politische Theologie", 19-21.

${ }^{69}$ Meier, Die Lehre Carl Schmitts: Vier Kapitel zur Unterscheidung Politischer Theologie und Politischer Philosophie.
} 
No obstante, en Schelling, ese giro no depara en un culto del poder estatal, bajo la forma del "Estado de excepción", ni en una sospecha, desde el Estado-nación y desde el nomos, de todo universalismo, sino, justamente, en la apelación a una forma de comunidad supraestatal que sería la única genuinamente cristiana. La teología política, en su dimensión apelativa, es aquí un llamado a una forma religiosa de cosmopolitismo. Así mismo, como forma de conocimiento, la teología política de Schelling tiene una diferencia notable con la de Schmitt: la de este último es más "política" que "teológica”. Si bien Schmitt, en su Teología politica II $^{70}$, esboza una cierta noción de Dios, una con ciertos paralelos con la de Schelling, esta permanece más bien implícita en su uso del término. En este último, en cambio, la dimensión política del término se funda en la pretensión de un conocimiento (especulativo e histórico-simbólico) de lo divino y solo sobre esa base, ligada a cierta antropología, llama a una decisión existencial. Schelling, en ese sentido, puede introducirse en el debate contemporáneo sobre la teología política trayendo consigo ese doble mensaje: la necesidad de des-estatalizar el concepto, lo cual va de la mano con desligar la incondicionalidad de lo divino de alguna forma de coerción, y la necesidad de restringir su uso a posturas que partan de una pretensión de elaborar un discurso racional sobre Dios (la teología strictu sensu) $\mathrm{m}$ y no de una alusión ensayística a las raíces religiosas de ciertos fenómenos seculares.

La teología de Schelling es ciertamente antipolítica, si se la interpreta en términos de repensar el fundamento de las instituciones políticas y, en particular, del Estado. No obstante, no podría decirse por eso -como lo presupone la postura estadocéntrica de muchos de sus intérpretes- que no hay aquí un pensamiento político. Lo que hace político un pensamiento no es solo de qué habla, o sea, cuál es su objeto, sino a qué apunta y frente a qué se posiciona.

La teología de Schelling es, por tanto, metapolítica, si se la piensa como una intervención del pensamiento filosófico en una particular coyuntura histórica cuyo propósito, siempre mediado por la voluntad del individuo concreto, es ofrecer una forma de resistencia político-cultural a la Modernidad con raíces en la tradición cristiana; una resistencia difícil de ubicar en el espectro de opciones político-partidistas disponibles en esa coyuntura y realizada en nombre de una comunidad por venir $y$, en última instancia, de la imposibilidad de conocer el fin último de la existencia comunitaria, el Ungrund puede ser leído como una "reserva escatológica” que suspende la ultimidad de todo régimen. De ahí se puede derivar, tanto una postura éticamente mediada de la plena desafiliación al Estado que espera el momento incalculable de la redención, como una obediencia puramente instrumental y no comprometida al

\footnotetext{
${ }^{70}$ Ver a Schmitt, Politische Theologie II: Die Legende von der Erledigung jeder Politischen Theologie.
} 
mismo. El espíritu anarquista de lo primero y el conservadurismo de lo segundo son caras de una misma moneda, esto es, de la teología política de Schelling.

\section{Bibliografía}

Anglet, Kurt. Der eschatologische Vorbehalt. Eine Denkfigur Erik Petersons. PanderbornMünchen-Wien-Zürich: Ferdinand Schöningh, 2001.

Appel, Sabine. Johann Wolfang von Goethe: Ein Porträt. Köln/Weimar/Wien: Böhlau Verlag, 2009.

Blumenberg, Hans. Die Legitimität der Neuzeit. Frankfurt am Main: Suhrkamp, 1988. Blumenberg, Hans, y Carl Schmitt. Briefwechsel 1971-1978 und weitere Materialen. Frankfurt am Main: Suhrkamp, 2007.

Böckenförde, Ernst-Wolfgang. "Politische Theorie und politische Theologie”. En Der Fürst dieser Welt, dirigido por Jacob Taubes, 16-25. Paderborn: Wilhelm Fink Verlag-Verlag Ferdinand Schöningh, 1983.

Bosteels, Bruno. Badiou and Politics. Durham/Londres: Duke University Press, 2011.

Bubner, Rüdiger. Polis und Staat. Grundlinien der politischen Philosophie. Frankfurt am Main: Suhrkampf, 2000.

Carrasco, Ana. "1809: die Figur Napoleons und der Begriff des Bösen in der Freiheitsschrift”. En Schellings Philosophie der Freiheit. Studien zu den Philosophischen Untersuchungen über das Wesen der menschlichen Freiheit, editado por D. Ferrer y T. Pedro, 69-80. Würzburg: Ergon Verlag, 2012.

Cesa, Claudio. "Friedrich Wilhelm Joseph Schelling”. En Pipers Handbuch der politischen Ideen 4, dirigido por Herfried Münckler e Iring Fetscher, 226-231. München-Zürich: Piper, 1986.

Das, Saitya Brata. The Political Theology of Schelling. Edinburgh: Edinburgh University Press, 2016.

Gordillo, Ignacio. "La política como pensamiento en la filosofía de Alain Badiou". Revista de Humanidades. Universidad Nacional Andrés Bello 27 (2013): 27-53. Disponible en: $\underline{\text { www.redalyc.org/articulo.oa?id=321227371002. }}$.

Habermas, Jürgen. "Dialektischer Idealismus in Übergang zum Materialismus. Geschichtsphilosophische Folgerungen aus Schellings Idee einer Contraction Gottes". En Theorie und Praxis. Sozialphilosophische Studien, por J. Habermas, 172-227. Neuwied: Luchtenhan, 1963. 
Hadot, Pierre. La filosofía como forma de vida. Barcelona: Alpha Decay, 2009.

Heidegger, Martin. Schellings Abhandlung über das Wesen der menschichen Freiheit (1809). Tübingen: Max Niemeyer, 1971. Disponible en: www.bard.edu/library/ arendt/pdfs/Heidegger-SchellingsAbhandlung.pdf

Hollerbach, Alexander. Der Rechtsgedanke bei Schelling. Quellen-Studie zu seiner Rechts- uns Staatsphilosophie. Frankfurt am Main: Vittorio Klostermann, 1957.

Jäger, Gertrud. Schellings politische Anschauungen. Berlin: Ebering, 1939.

Janke, Wolfang. Die dreifache Vollendung des Deutschen Idealismus. Schelling, Hegel und Fichtes ungeschriebene Lehre. Amsterdam-New York: Brill-Rodopi, 2009.

Losurdo, Domenico. Hegel und das Deutsche Erbe. Philosophie und nationale Frage zwischen Revolution und Reaktion. Köln: Pahl-Rugenstein, 1989.

Lütterfelds, Wilhelm. Das Erklärungsparadigma der Dialektik. Zur Struktur und Aktualität der Denkform Helgels. Würzburg: Königshausen \& Neumann, 2006.

Marx, Karl, y Friedrich Engels. Ausgewählte Werke I. Berlin: Dietz Verlag, 1987.

Meier, Heinrich. Die Lehre Carl Schmitts. Vier Kapitel zur Unterscheidung Politischer Theologie und Politischer Philosophie. Stuttgart: J. B. Metzler, 2009.

Novalis. Die Christenheit oder Europa. Krefeld: Scherpe Verlag, 1947.

Nygren, Anders. Eros und Agape. Gestaltwandlungen der christlichen Liebe. Gütersloh: Verlag von C. Bertelsmann, 1930.

Oesterreich, Peter. Das gelehrte Absolute. Metaphysik und Rhetorik bei Kant, Fichte und Schelling. Darmstadt: Wissenschaftliche Buchgesellschaft, 1997.

Ramírez Escobar, Carlos Andrés. "Patologías de la razón. Mal e ideología en Schelling”. En El mal. Seis variaciones: Pericles, Kant, Hume, Schelling, Nietzsche, Arendt, 109-60. Cali: Sello Editorial Javeriano, 2013.

Rancière, Jacques. El desacuerdo. Política y filosofía. Buenos Aires: Nueva Visión, 1996.

Ricoeur, Paul. El conflicto de las interpretaciones. Ensayos de hermenéutica. Buenos Aires: Fondo de Cultura Económica, 2003.

Sandkühler, Hans-Jörg. Freiheit und Wirklichkeit. Frankfurt am Main: Suhrkamp, 1968.

Schelling, Friedrich Wilhem Joseph. Aus Schellings Leben in Briefen. Editado por G. L. Plitt. Leipzig: Hirzel, 1870. 
. Die Weltalter. Fragmente. In der Urfassungen von 1811 und 1813. München: Biederstein Verlag-Leibniz Verlag, 1966.

. Sämtliche Werke. Vol. I. Stuttgart und Augsburg: J. G. Cottafcher Verlag, 1856-1861.

. Sämtliche Werke. Vol. II. Stuttgart und Augsburg: J. G. Cottafcher Verlag, 1856-1861.

. Sämtliche Werke. Vol. V. Stuttgart und Augsburg: J. G. Cottafcher Verlag, 1856-1861.

. Sämtliche Werke. Vol. VII. Stuttgart und Augsburg: J. G. Cottafcher Verlag, 1856-1861.

Schmitt, Carl. Politische Theologie. Vier Kapitel zur Lehre von der Souveränität. Berlin: Duncker \& Humblot, 2009.

. Politische Theologie II. Die Legende der Erledigung jeder politischen Theorie. Berlin: Duncker \& Humblot, 1970.

Schneider, Anatol. Persönlichkeit und Wirklichkeit. Nachidealistische Schellingrezeption bei Immanuel Hermann Fichte und Christian Hermann Weiße. Würzburg: Königshausen \& Neumann, 2001.

Tilliete, Xavier. "Die Freiheitsschrift”. En Schelling. Einführung in seine Philosophie, editado por Hans Michael Baumgartner, 95-107. Freiburg und München: Alber, 1975.

Voegelin, Eric. Die neue Wissenschaft der Politik. Eine Einführung. München: Wilhelm Fink Verlag, 2004.

. The Collected Works of Eric Voegelin. Vol 17: Order and History. IV: The Ecumenic Age. Editado por Michael Franz. Columbia (MO): University od Missouri Press, 2000.

Žižek, Slavoj. The Indivisible Remainder. An Essay on Schelling and Related Matters. London-New York: Verso, 1996. 